\title{
Uma epizootia, duas notícias: a febre amarela como epidemia e como não epidemia
}

\author{
One epizooty, two media coverages: yellow fever as epidemic and as \\ non-epidemic
}

\author{
Una epizootia, dos noticias: la fiebre amarilla como epidemia y como no \\ epidemia
}

Claudia Malinverni | claudia.malinverni@usp.br

Universidade de São Paulo, Faculdade de Saúde Pública, Biblioteca CIR

São Paulo, Brasil

\section{RESUMO}

Ciclicamente afetado por epizootias de febre amarela silvestre, nos últimos nove anos o Brasil registrou a midiatização de dois desses episódios, com consequências distintas no cotidiano da saúde pública, em particular, e da população, de modo geral. No primeiro, em 2008, a intensa cobertura jornalística provocou um transbordamento da rede de sentidos da epizootia da sua dimensão epidemiológica para a dimensão cotidiana, o que acabou por configurar a doença como um objeto específico e independente que se instalou no cotidiano como uma epidemia midiática de febre amarela. Diferentemente, em 2017, a narrativa jornalística centrada na objetividade da informação factual, com grande ancoragem no discurso perito, manteve o fenômeno circunscrito à forma silvestre. Uma análise comparativa das notícias publicadas nos dois períodos permitiu observar que as diferenças no uso de repertórios e o enquadramento dos textos determinaram a produção do sentido epidêmico em 2008 e não epidêmico em 2017.

Palavras-chave: saúde pública; febre amarela; comunicação e saúde; jornalismo; práticas discursivas; produção de sentidos no cotidiano. 


\section{ABSTRACT}

Cyclically affected by epizootics of wild yellow fever, in the last nine years Brazil has recorded the mediation of two of these episodes, with distinct consequences in the public health daily, in particular, and of the population, in general. In the first, in 2008, intense journalistic coverage caused an overflow of the network of meanings of the epizootic of its epidemiological dimension to the daily dimension, which ended up configuring the disease as a specific and independent object that settled in the daily life as a media epidemic of yellow fever. Differently, in 2017, the journalistic narrative centered on the objectivity of factual information, with great anchorage in the expert discourse, kept the phenomenon limited to the wild form. A comparative analysis of the news published in the two periods allowed to observe that the differences in the use of repertories and the framing of the texts determined the production of the epidemic sense in 2008 and not epidemic in 2017.

Keywords: public health; yellow fever; communication and health; journalism; discursive practices; production of meanings in daily life.

\section{RESUMEN}

Afectado en ciclos por epizootias de fiebre amarilla silvestre, en los últimos nueve años el Brasil registró la mediatización de dos de estos episodios, con consecuencias distintas en el cotidiano de la salud pública, en particular, y de la población, de modo general. En el primero, en 2008, la intensa cobertura periodística provocó un desbordamiento de la red de sentidos de la epizootia de su dimensión epidemiológica hacia la dimensión cotidiana, lo que acabó por configurar la enfermedad como un objeto específico e independiente que se instaló en el cotidiano como una epidemia mediática de fiebre amarilla. En cambio, en el año 2017, la narrativa periodística centrada en la objetividad de la información fáctica, con gran anclaje en el discurso perito mantuvo el fenómeno circunscrito a la forma silvestre. Un análisis comparativo de las noticias publicadas en los dos períodos permitió observar que las diferencias en el uso de repertorios y el encuadramiento de los textos determinaron la producción del sentido epidémico en 2008 y no epidémico en 2017.

Palabras clave: salud pública; fiebre amarilla; comunicación y salud; el periodismo; prácticas discursivas; la producción de sentidos en el cotidiano.

Contribuição dos autores: a autora é responsável pelo texto

Declaração de conflito de interesses: não há

Fontes de financiamento: não há

Considerações éticas: não há

Histórico do artigo: Submetido: 05.jun.2017 | Aceito: 06.jun.2017 | Publicado: 30.jun.2017

Apresentação anterior: não há

Licença CC BY-NC atribuição não comercial. Com essa licença é permitido acessar, baixar (download), copiar, imprimir, compartilhar, reutilizar e distribuir os artigos, desde que para uso não comercial e com a citação da fonte, conferindo os devidos créditos de autoria e menção à Reciis. Nesses casos, nenhuma permissão é necessária por parte dos autores ou dos editores. 
Nos últimos nove anos, dois ciclos de epizootia de febre amarela silvestre, fenômeno recorrente no cenário brasileiro, chamaram a atenção do jornalismo de massa. O primeiro, no verão de 2008 , foi alvo de uma intensa e controversa cobertura, que mobilizou a imprensa nacional em todos os suportes (TV, rádio, jornais, revistas, internet), provocando um transbordamento da rede de sentidos da epizootia da sua dimensão epidemiológica para a dimensão cotidiana, o que acabou por configurar a doença como um objeto específico e independente, instituindo-se como uma epidemia midiáticai. O segundo, no início deste ano, a despeito de ter provocado um surto entre seres humanos de dimensões inéditas e com potencial para a espetacularização, recebeu um tratamento jornalístico oposto, centrado na objetividade da informação.

Entender as diferenças entre as duas narrativas é o foco desta análise comparativa, que toma como exemplo o jornal Folha de S.Paulo, no lastro de um trabalho de pesquisa que venho realizando desde 2009. De partida é importante pontuar que, ao contrário do que ocorreu na epizootia de 2008, quando a imprensa generalista deu à febre amarela uma intensa e incomum visibilidade, este ano, como veremos, a abordagem foi sóbria e equilibrada, tendo como eixo narrativo a informação factual do acontecimento amarílico, fortemente amparada nos postulados da comunidade científica e da autoridade de saúde pública. Uma sobriedade, reafirma-se, que se impôs a despeito do cenário de risco de 2017, dado pela expansão inédita da doença, marcada pelo avanço do vírus sobre regiões há décadas indenes à febre amarela - sem registro de circulação e/ou transição viral -, a exemplo do Rio de Janeiro, e do surpreendente número de casos confirmados até 25 de maio último.

Até a conclusão desta nota, segundo o Ministério da Saúde ii , dos 3.210 casos suspeitos notificados desde o início da epizootia, no último trimestre do ano passado, 778 (23,7\%) foram confirmados e 563 (17,5\%) permaneciam em investigação, dos quais 267 (62,2\%) evoluíram para óbito e outros 39 (9,1\%) ainda estavam em investigação. O número de casos confirmados em 2017 é nove vezes maior do que o registrado em 2000 - que com 85 casos era, até então, o maior da série histórica, iniciada em 1980 -, e quase 17 vezes o contabilizado em 2008, quando foram confirmados apenas 46 casos.

Essa aproximação numérica das "duas" epizootias suscita um primeiro questionamento: por que a epizootia mais "branda", a de 2008, se transformou jornalisticamente em uma epidemia de febre amarela e a segunda, de 2017, mereceu da imprensa uma abordagem cautelosa, assentada no que poderíamos nomear como bom jornalismo? Para responder precisamos, antes, entender que o processo de produção da notícia, qualquer que seja, ocorre sempre em um contexto sócio-histórico que permite a captura e transformação pelos meios de comunicação de alguns acontecimentos cotidianos em mensagens (formas simbólicas) em detrimento de uma infinidade de outros. Implica dizer, como ressalta John B. Thompson ${ }^{1}$, que os sentidos das mensagens produzidas e transmitidas midiaticamente só podem ser examinados a partir de contextos sociais estruturados. Assim, antes de seguirmos, é importante uma breve contextualização do cenário brasileiro nos dois períodos analisados.

A epidemia midiática teve como pano de fundo o início do segundo mandato presidencial do petista Luiz Inácio Lula da Silva, que, em março de 2007, havia nomeado o sanitarista José Gomes Temporão ministro da Saúde. No campo da saúde pública, parlamentares governistas e da oposição travavam uma acirrada disputa pela renovação da CPMF. Pouco antes de detectada a epizootia amarílica pelo sistema nacional de monitoramento, em meados de dezembro de 2007, o Senado Federal havia rejeitado a prorrogação da contribuição. Importante complementação ao orçamento do SUS, a defesa da CPMF foi conduzida pessoalmente por Temporão, que rejeitava o viés tecnocrático das ações ministeriais. Titular do ministério

i O fenômeno da epidemia midiática de febre amarela, em 2008, é amplamente discutido em: Malinverni C. Epidemia midiática: um estudo sobre a construção de sentidos na cobertura da Folha de S.Paulo sobre a febre amarela, no verão $2007-2008$ [dissertação]. São Paulo: Faculdade de Saúde Pública da Universidade de São Paulo; 2011. E em: Malinverni C. Epidemia midiática de febre amarela: desdobramentos e aprendizados de uma crise de comunicação na saúde pública brasileira [tese]. São Paulo: Faculdade de Saúde Pública da Universidade de São Paulo; 2016. 
até o fim do Governo Lula, em dezembro de 2011, Temporão esteve sempre na linha de frente do debate político em torno das questões da saúde pública, o que, segundo ele, levou a embates públicos, muitos deles travados pela e com a imprensa, antes e depois da epizootia ${ }^{2}$.

Já a epizootia de 2017 se desenrolou sob o governo do peemedebista Michel Temer, cuja ascensão à presidência ocorreu com o afastamento da presidenta Dilma Roussef, em 31 de agosto de 2016. Controverso desde o início, o processo parlamentar que desaguou no impedimento de Dilma teve amplo e explícito apoio das principais corporações de mídia do país. Por outro lado, o ministro da Saúde do Governo Temer é Ricardo Barros, eleito deputado federal no Paraná pelo Partido Progressista tendo como maior doador individual de sua campanha, em 2014, Elon Gomes de Almeida, sócio do Grupo Aliança, administradora de planos de saúde. Engenheiro e empresário, o atual ministro defende o fim da universalidade do SUS e a criação de planos populares de saúde, que representam uma ameaça ao sistema público de saúde.

É, portanto, à luz desses cenários distintos que devem ser entendidas as práticas discursivas e os sentidos produzidos midiaticamente pelas duas epizootias, que, por contraposição de uma à outra, são reveladoras da construção da epidemia midiática de febre amarela como um fato social, na perspectiva de Aragaki, Piani, Spink 3 .

Assim, a análise comparativa aqui proposta, focada especificamente nos sentidos produzidos jornalisticamente, evidencia um primeiro aspecto relevante que diferencia as duas coberturas, a visibilidade. Em 2008, sob um contexto político e institucional completamente diverso do atual, a epizootia - então concentrada na região Centro-Oeste, com destaque para o Distrito Federal - foi classificada pela autoridade sanitária (Ministério da Saúde) e boa parte da comunidade perita (técnicos e pesquisadores) como dentro da normalidade epidemiológica, logo, evoluindo segundo as expectativas técnico-científicas. A imprensa de massa (portanto, generalista) discordou. A divulgação com destaque, pelo jornal Correio Braziliense, do primeiro caso suspeito registrado em Brasília (um funcionário do alto escalão do Ministério da Cultura) foi a senha para o agendamento jornalístico da febre amarela em escala nacional e, como dito, por diferentes meios de comunicação. A partir daí, e ao longo de quase dois meses, entre o final de dezembro de 2007 e $o$ início de fevereiro de 2008, o aparato midiático generalista manteve uma cobertura intensa do evento, que foi marcada pelo excesso de exposição do tema e pela seleção de repertórios de risco que salientavam a tese de urbanização da doença.

No primeiro recorte temporal, 21/12/2007 a 29/02/2008, que compreende a publicação da primeira e da última matéria circunscrita ao fenômeno da febre amarela midiática, foram localizadas 120 matérias, das quais 118 foram analisadas (veiculadas em 47 edições) ${ }^{i i i}$. Dois conceitos sustentam o pressuposto da visibilidade: acumulação, uma vez que o assunto foi abordado continuamente em seguidas edições e por um longo período de tempo, e onipresença, dada pela exposição do tema em diversas editorias, inclusive naquelas de natureza política, como veremos a seguir.

Utilizando exatamente o mesmo recorte (21/12/2016 a 28/02/2017), na cobertura deste ano foram localizados 75 textos, tendo sido analisados 71, publicados em 21 edições. Ou seja, embora do ponto de vista epidemiológico o evento de 2017 tenha sido consistentemente mais intenso, o volume de matérias publicadas pelo jornal foi cerca de 40\% menor do que em 2008.

Outro aspecto relevante desta análise é da ordem dos sentidos. Há nove anos, a construção da narrativa envolveu três grandes estratégias discursivas epidêmicas: "a doença fora de controle", com foco no "crescimento progressivo" do número de casos suspeitos; "o inimigo letal", centrada nas taxas de letalidade

iii As matérias que formam os corpora analíticos de 2008 e de 2017 foram veiculadas na versão digital da Folha de S.Paulo, disponível exclusivamente para assinantes do jornal ou do portal UOL. Para localização das matérias da primeira cobertura foi utilizado o termo "febre amarela 2008", em campo de busca próprio do arquivo eletrônico do jornal, então disponível no portal UOL. Em razão de mudanças na plataforma de acesso ao acervo, a pesquisa referente à cobertura de 2017 foi feita no link http://acervo. folha.uol.com.brl, na opção "busca avançada", utilizando o termo "febre amarela". Todas as matérias incluídas na pesquisa foram arquivadas em Word (2008) e PDF (2017), seguindo-se posteriormente à leitura de cada texto. 
e na sintomatologia/tratamento da doença; e a tese da urbanização, dada pela "transmissão generalizada", sentido produzido a partir da omissão da área de transmissão, que no caso da epizootia é rural, dificultando para o público leitor (na edição analisada em 2008, concentrado na capital paulista e na Grande São Paulo, portanto, áreas urbanas) a demarcação territorial do evento. Sobre essa última estratégia é importante ressaltar que a omissão do termo "silvestre" tornou discursivamente as duas formas (silvestre e urbana) um mesmo e único evento ${ }^{4}$.

Em 2017, ao contrário, a demarcação linguística do ciclo silvestre foi constante. Desde a primeira matéria ("Suspeitas de febre amarela crescem em MG", 12/01/2017), sobretudo quando a notícia remetia ao número de casos, o local de sua ocorrência foi constantemente demarcado:

\section{[...] Todas as vítimas trabalhavam na zona rural ou eram pessoas que estiveram no campo recentemente}

[...] Segundo o ministério, todos os casos são de febre amarela silvestre. A transmissão ocorre por meio de um ciclo que envolve primatas, como macacos, e mosquitos, como o Haemagogus, que por sua vez pode infectar pessoas não vacinadas. Já a febre amarela urbana, que é transmitida pelo mosquito Aedes aegypti, não é registrada no Brasil desde $1942{ }^{5}$.

Ainda no âmbito da estratégia "transmissão generalizada", a palavra-chave da cobertura de 2008 foi "epidemia", que se caracteriza pela ocorrência de surtos de uma doença de modo simultâneo em diferentes regiões, quando, na verdade, tratava-se de um surto, aumento repentino do número de casos de uma doença em uma região específica.

Na edição tomada como ápice do enquadramento epidêmico de $2008^{6}$, a de 14 de janeiro, a febre amarela foi manchete de capa ("Ministro vai à TV e nega epidemia de febre amarela") e destaque principal da editoria Cotidiano, com seis textos. No dia seguinte, 15 de janeiro, a Folha publicou seu primeiro editorial acerca do evento, indicando a relevância do tema para os donos do jornal. Nesse pequeno recorte do corpus de 2008 a palavra "epidemia" (e duas variáveis, "epidemias" e "não-epidemia") aparecem dez vezes, enquanto "surto", que era o que de fato estava em curso, apenas uma. Em contrapartida, na totalidade do corpus de 2017 (71 matérias) a palavra "epidemia" aparece apenas quatro vezes, duas delas no editorial "Febre de vacinas" (27/01). Exatamente para afastar a tese de evolução epidêmica da doença, o texto é peremptório: "[...] Não se pode falar de epidemia no caso da febre amarela [...]”. Em todos os textos em que havia caracterização do evento, o jornal empregou o termo "surto", conforme indica outro excerto do mesmo editorial: "O atual surto se caracteriza pela modalidade silvestre [...]".

Em 2008, os eixos narrativos "crescimento progressivo" e "inimigo letal" eram frequentemente articulados, inclusive nas 15 chamadas de capa sobre a febre amarela, 12 das quais publicadas quase consecutivamente, em que se destacam repertórios que explicitavam sentidos de descontrole e letalidade da febre amarela ("primeira morte"; " $2^{\mathrm{a}}$ morte"; " $5^{\mathrm{a}}$ morte"; " 7 mortes"; " 8 o total de mortes"; " 9 a morte"). Em 2017, o evento mereceu oito capas, mas em apenas duas o número de óbitos foi destacado: "Ministério admite, após 8 mortes, surto de febre amarela" (19/01) e "Cidades paulistas têm três mortes por febre amarela" (24/01).

Outra diferença importante diz respeito à abordagem do jornal sobre a vacinação antiamarílica. Em 2008, uma narrativa em forma de fábula alçou a vacina à condição de "poção mágica", apresentada como um dispositivo capaz de proteger a população do "inimigo letal" de modo "infalível". Nessa perspectiva, a imprensa passou a atuar como porta-voz do uso irrestrito da vacina, de modo geral sem explicitar seus potenciais efeitos adversos. Então, a demanda explodiu, inclusive naquelas regiões que estavam fora das áreas de ocorrência da doença, clássicas e/ou de transição viral. Para se ter uma ideia do impacto desse sentido sobre o Programa Nacional de Imunizações (PNI/MS), entre o final de dezembro de 2007 (primeiras notícias) e 22 de fevereiro de 2008 (esgotamento noticioso) foram distribuídas aos estados e ao Distrito 
Federal mais de 13 milhões de doses da vacina. Desse total, 7,6 milhões de doses foram aplicadas em pouco menos de dois meses, 6,8 milhões só em janeiro. Um dos três fabricantes mundiais pré-qualificados pela Organização Mundial da Saúde (OMS), no período, o Brasil não só suspendeu a exportação do antiamarílico, como também apresentou um pedido de empréstimo de quatro milhões de doses do estoque de emergência global. Com a explosão da demanda, no início de fevereiro daquele ano, o Sistema Nacional de Vigilância de Eventos Adversos Pós-Vacinação (EAPV-PNI/MS) já registrava 43 casos de reações adversas à vacina, mais do que o dobro do total de casos provocados pelo mosquito (19 casos confirmados entre dezembro de 2007 e 31 de janeiro de 2008)7.

O estado de São Paulo, que até 2008 tinha mais da metade do seu território livre da circulação do vírus, foi vice-campeão de doses aplicadas (mais de 2,4 milhões), atrás apenas de Goiás (quase 2,8 milhões), cuja totalidade do território é endêmica desde o início da década de 2000. Só na cidade de São Paulo foram aplicadas 428.337 doses, mais de cinco vezes do que em 2007 (79.666). São Paulo também registrou o maior número de reações adversas do país: 187 eventos pós-vacinais, 81 a mais do que Goiás. No período analisado ocorreram quatro óbitos por febre amarela vacinal, todos em território paulista (dois na capital e um em Embu-Guaçu, na Grande São Paulo, até hoje livres do vírus, e um em Rincão, no interior, à época ainda classificada como indene). Anote-se que esse número representou mais da metade dos óbitos pósvacinais registrados pelo EAPV entre 1999 e 2007.

O discurso a favor da vacinação teve no artigo "Alerta amarelo!", publicado pela jornalista Eliane Cantanhêde, apresentada então como uma das jornalistas de política mais influentes do jornal, na coluna Pensata, exclusiva da Folha Online, seu exemplo mais emblemático. O uso destacado, e bastante equivocado, de repertórios de risco transformou o texto, parcialmente reproduzido a seguir, em exemplo de mensagem alarmista em saúde e rendeu à jornalista o epiteto de "musa da febre amarela", segundo o ministro Temporão:

Com sua licença, vou usar este espaço para fazer um apelo para você que mora no Brasil, não importa onde: vacine-se contra a febre amarela! Não deixe para amanhã, depois, semana que vem... Vacine-se logo! A febre amarela é uma doença infecciosa causada por vírus e pode ser fatal. Hoje mesmo (terça, o8/o1), morreu um homem de 38 anos em Brasília, plena capital da República, com febre alta, dores musculares, náuseas e vômitos. Possivelmente, foi vítima da doença. O alerta nem é mais amarelo, já é vermelho. E a vacina é altamente eficaz. Tomou, está livre da doença [... $]^{i v}$

Em contraposição, na cobertura de 2017 o enquadramento da vacina pode ser classificado como cauteloso. Já na segunda matéria, "Vacina contra a febre amarela requer cautela", destacada em chamada de capa (13/o1), depois de demonstrar os riscos da vacinação indiscriminada, o texto alerta: “[...] Por isso, é preciso seguir à risca as orientações das autoridades sanitárias sobre quais regiões e grupos populacionais devem ser vacinados" vv.No editorial já citado ("Febre de vacinas", 27/01), a preocupação com o aumento da demanda vacinal em regiões sem recomendação, que àquela altura já sinalizava um possível desabastecimento nas áreas de surto, a abordagem investe na prudência: "Compete ao poder público distribuir doses de maneira eficiente aos locais que de fato necessitam delas. Precisa ainda esmerar-se mais na comunicação sobre quem deve vacinar-se e onde, para prevenir uma epidemia de pânico e a desorganização geral do sistema". Antes, em outro editorial (“Alerta amarelo”, 18/o1), rememorando um dos mais graves desdobramentos da

iv Cantanhêde E. Alerta amarelo. Folha Online (Grupo Folha) [Internet]. 2008 jan. 09 [citado em 2017 jun. 07]: Pensata. Disponível em: http://www1.folha.uol.com.br/folha/pensata/elianecantanhede/ult681u361459.shtml

v Collucci C. É preciso cautela com a vacinação indevida contra febre amarela. Folha de S.Paulo, São Paulo, 13 jan. 2017. Disponível em: http://www1.folha.uol.com.br/cotidiano/2017/01/1849447-e-preciso-cautela-com-a-vacinacao-indevida-contra-febreamarela.shtml 
epidemia midiática de febre amarela, o jornal apontou o risco da vacinação sem recomendação: “[...] Em meio a uma corrida indiscriminada por vacinas em 2007 e 2008, houve oito casos de reação adversa grave à vacina, com seis mortes”. Além dos dois editoriais, a Folha explicitou em diferentes matérias e edições informações sobre a população-alvo da vacina e os riscos de efeitos adversos.

Embora tenha pairado sobre o sistema nacional de imunizações um eventual desabastecimento chegando mesmo a ser detectada a falta pontual do imunobiológico em algumas regiões do país, sobretudo naquelas em que o surto já tinha sido confirmado (Minas Gerais, Espírito Santo e São Paulo) ou nas quais surgiram casos inesperados, como no Rio de Janeiro, em março - não houve no país uma "corrida pela vacina", como a registrada em 2008. Ao longo da epizootia de 2017, o aumento da demanda vacinal esteve majoritariamente atrelado às recomendações do ministério e das secretarias estaduais e municipais de saúde, a reboque das ações de contenção do vírus, e não do noticiário.

Nesse quadro geral comparativo, contudo, um aspecto diferencial entre 2008 e 2017 é particularmente evidente: a politização (2008) e a despolitização (2017) do evento. Há nove anos, a narrativa sobre a epizootia teve uma contundente participação dos articulistas de política do jornal, sendo o tema destacado em várias edições seguidas nas editorias Opinião e Brasil, espaços dedicados prioritariamente a assuntos políticos e econômicos (37 de 188 textos foram publicados como editorial, nota e artigo de opinião). Nesse recorte analítico, destacou-se a participação de Cantanhêde que, além do artigo "Alerta amarelo!", produziu para a versão impressa da Folha três artigos sobre o tema, tendo ainda colaborado com uma reportagem publicada na editoria Cotidiano. À jornalista juntaram-se o colunista Elio Gaspari (dois artigos), o senador José Sarney (um artigo), Renata Lo Prete, então responsável pela coluna de política Painel (duas notas) e dois editoriais. Durante todo o período, apenas um artigo foi assinado por especialista.

Já em 2017, a epizootia foi tema de apenas cinco artigos de opinião. Dois deles foram assinados por especialistas (o presidente da Sociedade Brasileira de Dengue/Arboviroses, Artur Timerman, em 20/01, e o secretário estadual de Saúde de São Paulo, David Uip, em 13/02). No período analisado, somente três articulistas de política abordaram o tema, um deles ressaltando a importância de manter uma vigilância atenta e uma comunicação precisa acerca da vacinação (27/01), enquanto os outros dois usaram a febre amarela como metáfora do quadro político nacional e paulistano, mas de maneira breve - Gaspari, em 22/01, e Tati Bernardi, em 27/01.

De modo geral, o tratamento jornalístico dispensado ao discurso oficial nos dois períodos também foi diferente. Em 2008, o discurso de normalidade epidemiológica da autoridade sanitária, principalmente do Ministério da Saúde, foi invariavelmente relativizado para baixo, combinado com a saliência das falas de especialistas que defendiam a tese de urbanização da febre amarela ou apontavam falhas na ação ministerial. Entre os textos dessa natureza, destaca-se a entrevista com uma especialista em saúde pública da Universidade de Harvard (EUA) em que é listada uma série de recomendações às autoridades brasileiras para o enfrentamento da epizootia. Ressalte-se que estas já tinham sido divulgadas pelo Ministério da Saúde em dois documentos oficiais ("Material de apoio para jornalistas" e "Temporão descarta epidemia de febre amarela"), em 9 de janeiro, portanto seis dias antes da entrevista. Não foi localizada no jornal qualquer referência aos documentos, que descrevem as principais medidas de vigilância da febre amarela, entre elas a vacinação da população que vive ou viaja para áreas de risco, medida destacada pela especialista estadunidense. Já em 2017, por outro lado, o discurso ministerial foi frequentemente valorizado como fonte de informação.

O trajeto da narrativa midiática sobre a epizootia em 2017 indica que a cobertura jornalística centrada numa abordagem cautelosa e ancorada no discurso perito minimizou a percepção social dos riscos envolvidos no agravamento do evento amarílico, ao menos fora das áreas em que o surto ocorreu. De modo oposto, em 2008 essa percepção foi ampliada pela mídia jornalística, que tencionou a rede de sentidos da doença até que ela extrapolasse o campo circunscrito da saúde se instalando, de modo generalizado, no 
cotidiano da população como uma epidemia fora de controle, com consequências graves, que se traduziram no grande número de reações adversas à vacina, quatro delas resultando em mortes.

Não tivesse se desenrolado em contexto político-institucional tão diverso, talvez fosse possível deduzir que a não epidemia midiática de 2017 foi resultado de um aprendizado advindo das consequências da epidemia midiática de 2008, capaz de mudar as práticas do jornalismo de massa na abordagem do tema. Não sendo esse o quadro geral, restará sempre uma dúvida: se fosse a petista Dilma Rousseff e não o peemedebista Michel Temer a presidir o país, teríamos em 2017 uma febre amarela midiática?

A análise aqui proposta não permite extrapolar o plano das conjecturas, uma vez que está limitada pelo recorte escolhido, qual seja, lançar luz apenas sobre alguns eixos narrativos das duas coberturas. Uma eventual resposta demanda, portanto, um estudo aprofundado dos diferentes aspectos e atores envolvidos na produção dos sentidos sobre as duas epizootias, inclusive o papel das instituições públicas nos processos de comunicação de uma e de outra cobertura.

De qualquer maneira, ela é ilustrativa da capacidade que tem a imprensa, particularmente em sua vertente de massa, de produzir fatos sociais, logo, instituir realidades, segundo os repertórios e enquadramentos que escolhe usar. Aqui, vale uma última observação que pode nos ajudar a entender por que as notícias sobre a febre amarela nos dois períodos produziram sentidos tão diversos. É preciso ter em perspectiva que as notícias não são "espelho" da realidade, mas resultado da interação simultaneamente histórica e contemporânea dos acontecimentos, que ocorrem em superabundância no cotidiano, com as forças pessoal, social, ideológica, cultural, dos meios físicos e técnicos de fixação e transmissão da informação midiatizada. Essas forças são moduladas por fatores mercadológicos e organizacionais (lucro, regras empresariais, competição entre editores e editorias, recursos humanos e materiais, hierarquia e organização interna, burocracia) e pessoais (constrangimentos temporais, éthos e ideologia do jornalista e da empresa jornalística $)^{8-9}$. Entendendo o processo de produção das notícias segundo essa abordagem, é possível afirmar que esse processo determinou a produção de duas "febres amarelas", completamente distintas entre si, a primeira epidêmica (2008), a segunda (2017) não epidêmica. Mas, a despeito dessa distinção, ambas são o resultado de contextos macropolíticos e institucionais específicos que influenciaram as abordagens e definiram o enquadramento da narrativa, produzindo por isso diferentes sentidos e, consequentemente, diferentes impactos sobre o cotidiano.

\section{Referências}

1. Thompson JB. A mídia e a modernidade: uma teoria social da mídia [Internet]. Avritzer L, tradutor. 15. ed. Rio de Janeiro: Vozes; 2014 [citado em 2015 out. 22]. Disponível em: <http://www.bocc.ubi.pt/pag/ sousa-jorge-pedro-construindo-teoria-da-noticia.pdf>.

2. Malinverni C. Epidemia midiática de febre amarela: desdobramentos e aprendizados de uma crise de comunicação na saúde pública brasileira [tese]. São Paulo: Faculdade de Saúde Pública da Universidade de São Paulo; 2016.

3. Aragaki S, Piani PP, Spink MJP O uso de repertórios linguísticos em pesquisa. In: SpinkMJP, Brigagão JIM, Nascimento VLV, Cordeiro MP, organizadores.A produção de informação na pesquisa social: compartilhando ferramentas. Rio de Janeiro: Centro Edelstein de Pesquisas Sociais; 2014. p. 229-47.

4. Malinverni C, Cuenca, AMB, Brigagão JIM. Epidemia midiática: produção de sentidos e configuração social da febre amarela na cobertura jornalística, 2007-2008. Physis: RSaúde Coletiva [Internet], 2012 [citado em 2015 out. 17];22(3):853-71. Disponível em: http://www.scielo.br/pdf/physis/v22n3/02.pdf.

5. Collucci C, Cancian N. Caderno Cotidiano. Folha de S.Paulo, 12/01/2017.

6. Malinverni C. Epidemia midiática: um estudo sobre a construção de sentidos na cobertura da Folha de S.Paulo sobre a febre amarela, no verão 2007-2008 [dissertação]. São Paulo: Faculdade de Saúde Pública da Universidade de São Paulo; 2011. 
7. Brasil. Ministério da Saúde. Secretaria de Vigilância em Saúde. Situação da febre amarela no Brasil 2007 e 2008. Boletim Epidemiológico, Brasília, 22 fev. 2008 [citado 9 out. 2011]. Disponível em: http://portal. saude.sp.gov.br/portal/arquivos/pdf/boletimfa 220208.pdf.

8. Traquina N. O que é jornalismo. 2. ed. Lisboa: Quimera; 2007.

9. Sousa JP. "Por que as notícias são como são?" Construindo uma teoria da notícia. Biblioton line Ci Comunic. 2002;13(4):2011. 